\title{
Changes of Intermarriage between Upper Classes of Yi Nationality in Dian \& Qian Region since Ming and Qing Dynasty and the Causes
}

\author{
Qianfang Shen \\ School of Human Science, Quqing Normal University \\ Qujing 655011, Yunnan, China \\ E-mail:shqf1228@yahoo.com.cn \\ Li Cheng \\ School of Human Science, Quqing Normal University \\ Qujing 655011, Yunnan, China \\ E-mail: chengli20001123@sina.com
}

\begin{abstract}
After the ancestors of Yi Nationality stepped into the class society, their traditional marriage was characterized by hierarchical endogamy, national endogamy, and levirate, etc. However, with rapid reformation of Yi Nationality in Dian and Qian Region since Ming and Qing Dynasty, they had changed their original strict hierarchical system, social structure, national structure, economic structure and ideology, with increasing internal disparate development. The series of changes not only broke traditional marriage form, and challenged the hierarchical endogamy and national endogamy, but brought into emergence filiality and chastity of women in Yi Nationality due to living mode, customs and behavioral manners of inland immigrants.
\end{abstract}

Keywords: Dian \& Qian region, Upper classes of Yi Nationality, Intermarriage, Changes, Causes

Marriage is product of human evolution, and changes with continual development of the society. After the ancestors of Yi Nationality stepped into the class society, their traditional marriage was characterized by hierarchical endogamy, national endogamy, and levirate, etc. After implementation of chieftain system, chieftains were conferred by the emperor, and became a particular social class with the highest social status. They disdained to have intermarriage relations with those with low social status, so the situation of "intermarriage between chieftains and different nationalities" within Yi Nationality. However, with rapid reformation of Yi Nationality in Dian and Qian Region since Ming and Qing Dynasty, they had changed their original strict hierarchical system, and their originally confirmed intermarriage relation was difficult to be maintained, because they had continually changed the traditional intermarriage concept. Meanwhile, social structure, national structure, economic structure and ideology within that region had also been changed to different extents. Internal disparate development was aggravated, which caused the traditional marriage to be gradually broken. Therefore, not only hierarchical endogamy and national endogamy were challenged, but filiality and chastity of women in Yi Nationality arose, which further stimulated changes of social reality in this region.

\section{Changes of intermarriage between upper classes of Yi Nationality in Dian \& Qian Region since Ming and Qing Dynasty}

\subsection{Intermarriage between different social classes within Yi Nationality}

After territorial tribal chiefs were changed into officials in Yi Nationality in Dian \& Qian Region, the Qing Government adopted the policy of supporting dirt farmers in order to recover its economy, so quite a large number of Yi people broke away from control of chieftains and become free farmers. Meanwhile, under attack of landowner economy, some remaining chieftains became impoverished as a consequence of improper operation, and some didn't have children, 
while originally suppressed Black and White Yi people had an increasing social status because of proper operation, become newly born landowners and imitated chieftains. Originally strict hierarchical system was changed, and "differentiation of being gentle and simple by the black or white people" was replaced by economic status. Then, mutual intermarriage arose between different classes. For instance, Qiaojia Tuoche Tuqianhu Lu Tingying didn't have any heir, but he had a daughter called Lu Xunzhen, who had an uxorilocal marriage so as to succeed the family property. Long Sheng, the third son of Black Yi Long Yun, was married into Lu, changed with a name Lu Xunlin, and become the successor of Aduo Tuqianhu. During the times of chieftains, chieftains and Black Yi were not internuptial. For example, Qiong Bu Xuanfu Chieftain Ling Rulong married Yi Mwa as his concubine, which caused refusal among Bamen Yi, and they rushed out to rob her. After overthrow by the Revolution of 1911 of Qing Dynasty's reigning, chieftains lost their backer, so they sought for protection by changing their intermarriage style. In order to acquire support from Yunnan Warlord Long Yun, Adou Official An Shude married his distant niece Long Yinjing as his concubine. Furthermore, Black Yi also belonged to the exploiting class, while White Yi was an exploited class, so they didn't establish intermarriage relationship with each other. However, after the reformation, part of White Yi became the newly born landowners through their diligent labor and changing their operation manner. As a consequence, there appeared mutual intermarriage between these two classes. Such as, Black Yi Long Yuqing, one of the four major landowners in Zhenxiong, established affinity relations with Luo Shaoxuan, a White Yi landowner.

\subsection{Intermarriage between different nationalities}

Since Ming Dynasty, different degrees of changes had taken place in the social structure, national structure and economic structure in Yi Nationality with further reign of the central Dynasty upon Yi Nationality and with continual inburst of inland immigrants, and the internal developmental imbalance was aggravated. With proceeding of territorial tribal chiefs changed into officials, the Central Dynasty continued to send flexible officials, with an increasing reigning power. At the same time, traditional systems and culture of Yi Nationality suffered from strong attack. Original balance was broken, and the hierarchical system in those regions was further loosened in which the reformation was relatively thorough. The family concept became weak which was gradually replaced by the patriarchal clan system of Han Nationality and by the monogamous patrilineal small-family society. Lineage concept was gradually constituted by the economic status. Besides, different degrees of changes happened in activities of daily living in ideological field which was affected by Confucianism, so intermarriage between different nationalities increased gradually.

Since Ming and Qing Dynasty, there had had more records on intermarriage between upper classes in Yi Nationality in Dian \& Qian Region. The county government officer in Wuding Fengshi and Lijiang Naxi Nationality chieftain Mushi got married, which was to get protection from Mushi. Shuixi Anshi and Bozhou Yangshi got married because they needed mutual assistance and compromise. In Weining, after Tu was reformed into Liu, although chieftains had the highest social status and greatest authority among all classes in Yi Nationality, and they didn't want to have intermarriage relations with Black Yi and other reigned classes, they still had intermarriage relations with chieftains, and their social status descended. In order to maintain their power in terms of politics and economy, they began intermarriage with local powerful Han Nationality. As for such regions as Western Dian and Southern Dian which had developed economy, that was more common. For instance, Menghua Chieftain Zuoshi established intermarriage relationship with Fan, Yao, Chen, Liu \& Li, etc who were local powerful officials sent by the central plains of China, and with local tyrannicals so as to consolidate and strengthen his reigning. Nalou Pushi established intermarriage relationship with Hani and Han Nationality. As for Han litterateurs and merchants, they were more favored by chieftains in Yi Nationality. For example, during Qing Dynasty, Chen Ding went to Dian with his youngest uncle at the age of ten. Just one year later, his uncle died, and his older brother fell ill, so he didn't continue to hold the position. He was totally a stranger in a foreign land. Afterwards, his maternal uncle Qianshi made the acquaintance of the Chieftain Long in Yi Nationality during his trade of tabacco, so Chen Ding was left as a private tutor, and taught calligraphy. Then, his family circumstances took a turn for the better, and Chen Ding also got guide and support from his maternal uncle. He was sent from Qujing to Chieftain Long, who appreciated Chen Ding for his being literary and proficient in Seven Liberal Arts. So Long married his firstborn daughter of the first wife to Chen Ding. With his own experiences, Chen Ding introduced in detail his wedding ceremony and living customs, which offered specific historical records for us to have knowledge in intermarriage between upper classes of Yi Nationality under the circumstance of social reform at that time in Dian \& Qian Region. Furthermore, Black Yi Long Yun got married with his cousin at an early age in the Republic Period, and also married one Yi Nationality woman in Ludian as his concubine. Later, he continued to get married with Li Peilian, daughter of Han traditional Chiense medicine doctor Li Canting in Binchuan County. When Long Yun was imprisoned by Hu Ruoyu, Li Peilian, regardless of poverty and ruin, contacted former subordinates of Long Yun to help Long Yun escape from danger. Her magic and wisdom was far beyond that of ordinary housewives. In 1932 when Li Peilian passed away, Long Yun again was married with Gu Yingqiu, the daughter of Dian Army commander Gu Xiaoqi's daughter and who graduated from The Woman Normal University of National Beijing. Long Yun was accompanied by Gu Yingqiu in his later years. Long Yun's cousin also got married with Han bureaucrat Zhang Banghan. In his quotation of $<<$ Kuomingtang Character Biography $>>$, Hu Er recorded, "As a politician, his (Zhang Banghan) huge property 
enabled him to reestablish intermarriage relationship with Long Yun. Increasing intermarriage between Yi and Han Nationalities reinforced their mutual understanding. In his $<<$ Congratulations on Intermarriage between Yi Long Dekun \& Han Miss Zhu Guihua >>, Zhenxiong Scholar Chang Qinye of later Qing Dynasty spoke highly of "no discrimination of boundary, intermarriage between Yi and Han Nationalities, and of the necessity of being prosperous after intermarriage". This kind of intermarriage between different nationalities really reflected the mutual relations that no one can go along without each other in the process of Chinese development.

\subsection{Continual emergence of filiality and chastity among women in Yi Nationality}

Filiality and chastity was a shackle to women for their ethics in Chinese feudal society. Both the family and the court attempted to mould the image of a woman in terms of her ethics, then conferred honors on her, which became a common ethical behavior advocated by the whole society. What's more, women at that time were also willing to accept this moulding, because on their part, to be able to go down to history and to receive reward in a society, in which they were looked down upon, was an extreme honor both for themselves and for their families. Therefore, there didn't lack records of women with filiality and chastity.

Before Yuan Dynasty, this cultural background hadn't been formed in Yi Nationality in Dian, Chuan and Qian Region. They were still engaged through moon dance with no surprise at all, and there wasn't any prohibition on communication between virgin men and widows. If her husband died after marriage, the wife would be levirated within the family-tree members so long as she was at an age of marriage and childbirth, so as to avoid flow out of their assets. Therefore, either the official history or local history records hardly had any record about filiality and chastity among women in Yi Nationality. They were quite different from women in the central plains of China who followed such ethics as the three obediences and four virtues, and the three cardinal guides and the five constant virtues, etc.

However, since Ming and Qing Dynasties when Han people immigrated and there formed a mixed living among various nationalities, the Confucianism of Han culture got to Yi area. The exemplary role of Han immigrant women upon them made changes of different degrees happen in the living mode, customs, and behavioral patterns among Yi female, and they gradually accepted the concept of filiality and chastity. For instance, Long Yangshi, wife of the departed Chieftain Long Shengwu. She was good at Yi writing, and knew well the principle of right and wrong. Shengwu died at an early age, without any child. His wife was young, but according to the Yi custom that once the older brother died, his younger brother would marry his wife. So the younger brother threated Long Yangshi and forced her to levirate, without any human rationality. However, Long Yangshi had no choice but to pledge not to levirate with the threat of death. In order to break away from smuttiness, she asked for help from the government. Then she adopted Long Chengzong as her son, who afterwards entered Wu School, and who was the grandson of Zheng Ruiqi. When she died at the age of 60, she was conferred the title of "aamjuw" by the inspection institution. A mere look at historical records of this period, we can find virtue, filiality, chastity and integrity, and especially chastity. As for Yi female, they underwent the most hard and devious journey in their life, because in traditional culture of Yi Nationality, there had been a custom of levirate between the young brother of a departed husband and his wife and even between different generations. That is, the son married his stepmother after the death of his father, and the young brother of a departed husband married his wife. Therefore, the virtue of female contradicted vehemently with the traditional culture of their nationality. For example, Yang shi, wife of Long Shengwu, was oppressed day by day, almost without any human justice. In order to remain unmarried, she defied death to defend and tried hard to follow the custom. Finally, she got support from the feudal government and realized her purpose of remaining unmarried, so she was conferred the title of "aamjuw" by the inspection institution. It is obvious that the government adopted the protection policy upon those upper class female of chastity, heaped praise upon them, conferred honors on them, and influenced other ordinary Yi female through them, so as to achieve the purpose of eliminate Yi customs and follow requirements of the feudal society for female. However, whether they were entitled with "aamjuw" or "noble character", they had to achieve that at a heavy cost if they intended to break this traditional authority, although they had gained the so-called reputation under the social circumstance of that time. Also, they had to encounter more difficulties and hindrance than Han women. Although it was a fact, Yi female, especially upper class female had challenged the traditional culture. This, without doubt, was a great social progress which was a struggle against inherent customs in the historical conditions at that time. Originally, there were approximately a hundred sorts of Yi men and they never had any record in terms of chastity, and men and women and old and young sang and danced, rejoicing with wild excitement. Afterwards, wives died for chastity for their husbands, unmarried women kept their chastity, and female began to establish chastity concept for themselves.

\section{Causes for changes of intermarriage between upper classes of Yi Nationality in Dian \& Qian region since Ming and Qing Dynasty}

\subsection{Prevalence of Confucianism}

After establishment, Ming Dynasty continued to carry out chieftain system on the basis of Yuan Dynasty. In order to enable chieftains to obey dynasticism and know about monarch-subject etiquette, in 28th Year Hongwu, Zhu Yuanzhang made an imperial order to Libu that, "Chieftains in remote and border areas are all traditionary, and they rarely know 
about etiquette. If they are restricted too strictly, they might resist, and if not, they wouldn't follow centralized control. How to educate them? It should be like this: to set up confucianism teaching among chieftains in Yunnan and Sichuan, and to teach those talented among chieftains' sons, grandsons younger brothers and nephews. They should be taught etiquette of father and son and monarch-subject etiquette, so that they wouldn't resist the court, which is also one way to stabilize border areas". As for those chieftains who succeeded, they were required to enter a school for reading and learning etiquette, and enjoyed special treatment, so as to change "undesirable customs" of Yi Nationality. Under long-term influences of feudal culture, Yi upper classes, especially children of chieftains had similar customs to those of the central plains of China. Just as in his $<<$ Anshijiazhuanxu $>>$, Zhou Hongmo said, "An guan's living room, waref, clothes, food and drink, marriage, funeral, treatment of guests, and warding off calamity, etc, all followed etiquette of China. ... After death of An guan, his son An Guirong succeeded his title, and was good at reading all sorts of historical books. He set up a school to teach etiquette of minorities, so great changes took place to all sorts of old customs. The purpose of changing Yi with customs of China was attained.

During Qing Dynasty, the government not only required those succeeded officials above the age of 13 to learn etiquette in a school, and took over the succession starting from Confucianism. If any of younger generation of the nationality wanted to learn in the school, he had to pursue an official position together with Han people, so that he could benefit from the etiquette, while the Confucianism got increasingly popular and the violent custom was gradually changed. What was more important, on the basis of original Confucianism and academy in Yi area in Dian and Qian, the Qing government accepted lots of children of the nobility to learn Confucianism culture which was specially aimed at rise of charitable schools of such minorities as Yi Nationality, etc. That was an important approach for them to succeed and hold the official position. That was also aimed at influencing them through the Confucianism, making them recognize Han culture and gradually extending to such aspects as living style and behavioral habits, etc. At present, education on minorities in border area should attach great importance to their civilization education. Firstly, children of minorities close to Han Area should be taught. Once they get along with Han children for long, they can be taught emperor commandments. After they are familiar, then they can be taught Confucianism, with a time limit of six years. If they cannot learn well, they should be sent back, and other excellent children should be selected to teach. When they are successful in their school work, they should be sent to more distant areas to teach minorities, and after they accomplish their target, they are allowed to take part in imperial competitive examination. When children of nobility achieve their goals, they bring back this advanced culture to Yi Area, which in turn, promoted progress of Yi culture.

Influence of Confucianism caused changes of different degrees in endogamy, hierarchy, basic necessities of life, and gender differences of Yi upper classes. 9th year of Emperor Qianlong's reign (1744), Yunnan Xunfu Zhang Yun reported, "although minorities in Yunnan Province fall behind, they are relatively modest and indebted. In addition, they try to convince local people to follow rules and regulations of the central law. At present, women of all minorities also come to understand chastity. It is suggested that more than 370 schools should be established and teachers of Confucianism should be selected. So far, there have been quite lots of people among all minorities who are fond of reading.". That not only consolidated reign of the Qing Government, but also gradually became "a thinking motive for stimulating Yi upper young people to learn Confucianism". Affected by that, Yi upper class women also followed female virtues according to feudal ethics.

\subsection{Changes of customs after tribal chiefs being changed into officials}

According to research, in the process of cultural transition, what was firstly changed was the material level, then system level, later custom level and finally thinking and value level. Since a custom is a generally accepted and conventionalized standard and model, and a human relationship method for a certain group, it has a relevant stability and even conservatism, so characteristics of all nationalities are displayed. Of course, the custom is not without any change, because during a specific historical period, especially when the social reform and integration of nationalities were quickened, the custom could also reveal certain corresponding changes, which indicated recognition and convergence of one nationality to another.

Before Yuan Dynasty, it was difficult for foreign officials and immigrants to enter Yi area in Dian and Qian. Even if a minority of them could get in, most of them were assimilated. Since Ming Dynasty, vigorous implementation of Tuntian among armies and the people and entrance of Han immigrants into Yi area for residence changed the original Yi ghetto into a mixed living area of Yi and Han nationalities, etc. Furthermore, the proportion of Han people was gradually on the increase, and there emerged a situation of smaller indigenous population and more immigrants. After Qing Dynasty, Yi Nationality was further pressed towards mountain area. For instance, extensive reform of Qing Dynasty in northeast Dian and southern Guizhou killed quite a large quantity of innocent Yi people without mercy, which caused sharp fall of Yi population in these areas. Meanwhile, the government built flood ponds in Yi ghetto and implemented reclamation of immigrants, which caused fast increase of Han population in Yi area. As a consequence, whether in a thoroughfare or a remote village, there must be one from Jiangxi who opened a store or dealt with trade. However, in relatively developed area, it was inland people who dealt with trade over the years as frequently as one tatted, while 
Chu, Yue, Shu and Qian men took their wives and children to reside there all their life. They rented land of Yi people and earned a living who accounted for three or four out of ten or so.... Visitors did business there and took their families along with them who became more and more. What was more, those single men made an investment there, got married with Yi women, and could enter anywhere in villages there by depending on the identity of their wives. As a result, the original Han population in Yi ghetto increased sharply, which largely changed the demographic structure and social structure of local Yi society.

A boundary of Dian, Qian, Chu and Yue was formed, which was extended for five or six thousand Li. Great changed had happened to such ancient customs as tattooing and weapons. Differences of Yi Nationality from the central Plains of China were gradually diminished, and a peaceful scene appeared, which were unprecedent. Immigration of Han people not only brought in advanced inland production skills and labor tools, but had a significant effect upon customs of Yi Nationality, where there appeared the phenomena of "reclamation over the years, elimination of deserted land, assembly of businessmen, living together of Han and Yi people, and dense houses", which had no difference from inland situation.

Extensive immigration of inland Han people and the reform of tribal chiefs being changed into officials enabled Yi area which originally had the common practice of being rude to get rid of the former undesirable customs. Intellectuals were educated and reasonable and laboring people were diligent in ploughing. Deeply influenced by inland economy and culture, there was no difference in terms of dressing, food, marriage and funeral, and alternation of the four seasons among Han and Yi people. Change of upper classes of Yi Nationality would necessarily drive changes of customs of the people who were under their control. Such as, from Lydian to Republic of China, Hui population accounted for one third of Han population within the border, Yi population merely accounted for five percent, and Mongol people had vanished. Yi and Hui people were assimilated by Han people, only except that Hui people didn't eat pork as Han people did, and Yi people didn't sleep in the same bed with Han people, which were their own characteristics. Long-term living together with Han people, Yi people were affected by Han people in all aspects, and their living customs were gradually changed towards those of Han people.

\subsection{Rapid reduction of Yi population and exemplary role of Han women}

Reform of Ming and Qing dynasties in chieftains in Dian and Qian Yi Nationality usually underwent rebellion, suppression and rebellion again. During Tianqi years in late Ming Dynasty, the Shuixi chieftain An Bangyan united Yingning Xuanfushi She Chengming in Chuannan to revolt against the court and were suppressed, which aggravated disunion between upper classes within Shuixi. Such chieftains as Wozhe and Huasha etc, fought against each other vehemently for succession of officials, and all offered their land for being changed into an official. Ankun War was a continuation of She'an War, but it was a spent bullet. It was suppressed within one year, and although An Shengzu held the position of a chieftain again afterwards, still his power was diminished to a great extent.

It was estimated that there were over 10,000 rebelling chiefs, parties and accomplices who died and killed themselves by drowning themselves in a river or rolled into precipices. Thousands of hunted and arrested people were beheaded and chopped their rights hands. The number of minorities who were given to meritorious officers and soldiers as an award was also several thousands. There were almost ten thousand people who were approved to be emplaced again and who surrendered. There were hundreds of important criminals who were investigated and there were only tens of people who were not hunted down. After reform of chieftain areas in northeast Dian, original Wumeng chieftain Lu Wanzhong and Zhenxiong chieftain Long Qinghou were assigned to Jiangnan by Qing government. Altogether a couple hundred of tribal chiefs were sent to Dian to be interrogated by Anchashi Yi Xidao, among whom almost one hundred rebelling chiefs were killed, Mitie chief Lu Yongxiao was beheaded, and his wife Lu shi and other chiefs were captured in succession or died in the prison. Besides, after the reform, cruelty and greed of officials aroused more rebellion from local people. E Ertai maneuvered Han Tu soldiers in several southwest provinces for a sanguinary suppression and began large-scale destroy and thorough search. They either killed or dispatched those chiefs, leaving not a single consequence of sin.

Most chieftains were either killed or shifted inland, so quite a great many innocent Yi people were cruelly killed. Those survivals either fled into Liangshan area or were changed into Han Nationality or other nationalities under their protection, or moved to dense forests. As a consequence, the population of Yi Nationality was rapidly reduced. For example, Yi Nationality in Ludian only occupied five percent of Han population in the Republic Period. Weining was also an area in which Yi and Han people lived together and Yi population accounted for approximately $20 \%$. Due to rapid reduction of upper Yi classes, the intermarriage phenomenon wasn't able to be as common as before tribal chiefs were changed into officials, so it had to be adjusted to a certain extent.

As mentioned above, Han immigrants from the central plains of China during Ming and Qing Dynasty entered Yi Area by different means. And after tribal chiefs were changed into officials, again a large batch of inland Han people entered Yi Area and strengthened their connection with Yi Nationality. Their daily living behaviors, especially the values of moral outlook of Han women did play an exemplary role in Yi women. According to the study, there were 2 women of 
chastity during the dynasties of Han and Jin, 1 during the dynasties of Sui and Tang, 17 during Yuan Dynasty, 1295 during Ming Dynasty and 9645 during Qing Dynasty in Yunnan Province. There were so many women of chastity merely in Yunnan Province during dynasties of Ming and Qing, and the number was also great in Guizhou area. Since their names might be engraved in the memorial arch of chastity and go down to history because of their honors, that might be considered a realization of their self-value in which they took great pride. Lots of minority women also followed their steps as a result of their affection towards that. For instance, Zhu shi, the wife of Jin Yinglin, followed her mother to escape to Dianchi Lake from enemies, and drowned themselves after hearing that the enemy searched them in the sea. Tu people grieved for them, and buried them in the stilt. There were altogether eight women in Ren shi from Kunming, who escaped to Luomuwudao River from enemies during unrest of late Ming Dynasty. Afterwards, they were discovered by mutinous soldiers, and then drowned themselves one by one. Local Tu people engraved a stone tablet which said, "Place of death of the eight women from Ren shi." Local Tu people grieved for women of chastity in Han Nationality, and also engraved their stories, which indicated that local people had grown a kind of recognition to behaviors of Han women. Although this isn't a direct historical record to reflect Yi area, it can still be deduced that there may also exist similar situations in Yi area. Therefore, their behaviors had played an exemplary role in Yi women.

All in all, due to rapid social reform of Yi Nationality in Dian \& Qian Region during Ming \& Qing Dynasty, reinforcement of national communication, and changes of customs and ideological consciousness, official regime gradually took the place of tribal chief regime. Change of the social status of chieftains compelled them to adjust their traditional intermarriage pattern. Therefore, great changes happened to traditional marriage concepts, in which more and more upper classes in Yi Nationality established intermarriage relationship with those classes under their leadership and other nationalities, especially Han Nationality, and also played a demonstrative role for those people under their leadership. Meanwhile, elimination of Wei-so and flood ponds caused lots of Han soldiers and their families to live scattered in Yi Region. They lived together and got along well with Yi people, taught each other production skills and cultural knowledge, accepted mutual living customs and established intermarriage relationship with each other, which all promoted cultural progress and social development in Yi Nationality in Dian \& Qian Region.

\section{References}

(1985). Real Records on the Qing Emperor Shizong, Vol. 230. Zhonghua Book Company.

Chen, Ding. (2004). Record and Preface about Marriage of Chieftains in Dian and Qian Region, in Southwest China Literature Series. Lanzhou University Press, Vol. 119.

Cheng, JI, et al. (2006). Zhenxiong Records, Vol. 4, Renwuzhixia -- Lienv Zhuan, in Collection of Old Records of Zhaotong by Zhang, Kuanshou, (4). Yunnan People's Publishing House.

Compiling Committee of Qiaojiaxianzhi in Yunnan Province. (1997). Qiaojiaxianzhi. Yunnan People's Publishing House.

Descendants of Mangbufulong Shi. (1997). Poetic Prose Works of Mangbufulong Shi. Zhaotong Teacher's College's Library, Vol. 1, December.

Editing Group of Guizhou Province. (1986). Comprehensive Survey of Society and History of Miao Nationality and Yi Nationality in Northwest Dian. Guizhou Minorities Press.

Editing Group of Yunnan Province. (1987). Social and Historical Survey of Yi Nationality in Guizhou in Sichuan Province. Yunnan People's Publishing House.

Editorial Board of General History of China Yi Nationality. (1993). Outline of General History of China Yi Nationality. Yunnan Nationalities Publishing House.

Fan, Chuo \& Zhao Lvfu. (1985). Man Yi Customs, in Yunnanzhi jiaoshi, Vol. 8. China Social Sciences Press.

$\mathrm{Fu}$, Tingquan \& Jiang, Yingshu. (2006). Registered Residence of Zhaotong Zhigao, Vol. 2, in Collection of Old Records of Zhaotong by Zhang, Kuanshou, (1). Yunnan People's Publishing House.

Hall. (1984). The Yunnan Provincial faction, translated by Xie, Benshu, et al. Research Monographs, Research Institute of History, Academy of Social Sciences in Yunnan Province, No. 1.

Jiang, Nan. (1987). Long Yun Biography. Xingchen Publishing House.

Long, Yun \& Zhou, Zhongyue. (1949). Newly Compiled Yunnantongzhi, Vol. 133, Xuezhikaosi. Typographic copy.

Pan, Xianlin. (1999). Study on Ruling Group of Yi Nationality in Yunnan during the China Republic Period. Yunnan University Press.

Real Records on the Ming Emperor Hongwu, Vol. 239. Photocopy by Research Institute of History of the Central Academy and Codex from Beiping National Library (Taiwan).

Ren, Kecheng. (1948). Guizhou Tongzhi, Tumin Zhier (the Republic of China). Typographic copy. 
Shao, Xianshu \& Liu, Zhuosheng, et al. (1986). Social Survey of Yi Nationality in Hepinggouxiazhai of Liangshuijing Town, Xiantangfang District, Zhenxiong, in Survey on Yi Nationality in Yunnan. Yunnan People's Publishing House.

Shen, Haimei. (2001). Women's Life Studies in Yunnan in Ming and Qing Dynasties. Yunnan Education Publishing House.

The first China Historical Archives. (2000). Previous Archives of Yi Affairs Commented by Qing Emperors. Sichuan Nationalities Publishing House.

Xiao, Ruilin. (2006). Wumengjinian, Vol. 4, in Collection of Old Records of Zhaotong by Zhang, Kuanshou, (6). Yunnan People's Publishing House.

Xie, Shenglun. Dianqian Zhilue, Vol. 21, School, Election Customs. Handwritten copy in Qianlong Twenty years.

Yu, Yingshi. (1989). Modern Explanation of Chinese Thinking Traditions. Lianjing Publishing Company.

Zhang, Lvcheng. (2001). Caiyunbaiyong, Volume III, Bianmanfeng, in Yunnan Historical Materials (8) by Fang, Guoyu. Yunnan University Press.

Zhang, Ruike. (2006). Ludian County Tongzhi Data Continuation and Four Yi Customs, Republic of China Topography Data in Ludian County, in Collection of Old Records of Zhaotong by Zhang, Kuanshou, (6). Yunnan People's Publishing House.

Zhou, Hongmo. (1965). Anshijiazhuanxu, in Xie, Dongshan (Ming) et al: (Jiajing) Guizhoutongzhi, Vol. 12. Yunnan University borrowed Yunnan Library's collection of block-printed edition of Ming Jiajing Year 34 stored by Tianyige. 